\title{
Magnetic Susceptibility of Zr-Cu Binary Alloys
}

\author{
Seung-Pyo Hong ${ }^{1}$, Yeong-Mu Ko ${ }^{2}$ and Chung-Seok Kim ${ }^{1}$ \\ ${ }^{1}$ Department of Materials Science and Engineering, Chosun University, \\ 309 Pilmun-daero, Dong-gu, Gwangju, 501-795, Korea \\ ${ }^{2}$ Department of Dental Biomaterials, Chosun University, \\ 309 Pilmun-daero, Dong-gu, Gwangju, 501 795, Korea
}

The objective of this study is to investigate the magnetic susceptibility of $\mathrm{Zr}$-Cu binary alloys for their potential use as biomaterials with nullifying magnetic properties for magnetic resonance imaging diagnosis. The $\mathrm{Zr}$-Cu binary alloys were prepared using the arc-melting process with zirconium strips and oxygen-free copper. This binary alloy has two dominant phases consisting of $\alpha-\mathrm{Zr}_{\mathrm{r}}$ and $\mathrm{CuZr} \mathrm{r}_{2}$ intermetallic phase. The magnetic susceptibility of the $\mathrm{Zr}$-Cu binary alloys was extremely low, approximately $10^{-7}$; this level is approximately one order less than that of pure $\mathrm{Zr}$ and other commercialized metallic biomaterials. Consequently, $\mathrm{Zr}-\mathrm{Cu}$ binary alloys have the potential to be used as biomaterials with low magnetic property. [doi:10.2320/matertrans.M2014222]

(Received June 16, 2014; Accepted July 14, 2014; Published September 25, 2014)

Keywords: zirconium-copper, binary alloy, magnetic susceptibility, biomaterials

\section{Introduction}

Metallic materials have a significant clinical impact on the biomaterial industry because of their biomechanical properties and suitability for common sterilization processes. Many metals and alloys, such as gold, stainless steel, Co-Cr alloys and $\mathrm{Ti}$ alloys are now commonplace within the oral implant industry. Commercially, pure Ti and Ti6Al4V have become the most popular metals used for the endosseous parts of currently available dental implants, bone plates and artificial joints because they have excellent specific corrosion resistance and the greatest biocompatibility with bone. ${ }^{1-3)}$

Recently, magnetic resonance imaging (MRI), which is a medical imaging diagnosis tool used in radiology to investigate the anatomy and function of the body, has become an important diagnostic technique in orthopedics and brain surgery. This technique is widely used in hospitals for medical diagnosis, disease staging and follow-up without exposing the patient to ionizing radiation. Dental implants are used in the reconstruction of prosthetic defects in the oral cavity and in modern surgical methods in traumatology. These appliances present a concern from the viewpoint of the patient's safety and quality of MRI data. Metallic implants, such as stainless steel, Co-Cr alloys and Ti alloys, become magnetized in the strong magnetic field of the MRI instrument and produce artifacts on the image. ${ }^{4)}$ The areas that cause the artifacts on images are closely related to the magnetic susceptibility. ${ }^{5)}$ This susceptibility artifact is caused by metals, such as $\mathrm{Ti}, \mathrm{Co}$, and stainless steel, inside the body. ${ }^{6,7)}$ Therefore, metallic implants with a low magnetic susceptibility are preferable for surgery performed with the assistance of an MRI.

Recently, $\mathrm{Zr}$ alloys have attracted interest as biomaterials due to their excellent mechanical properties and low magnetic susceptibility. Kondo et al. reported that the magnetic susceptibility of $\mathrm{Zr}-\mathrm{Nb}$ was half that of Ti-6Al$4 \mathrm{~V} .{ }^{8)}$ Additionally, Suyalatu et al. showed that the magnetic susceptibility of $\mathrm{Zr}$-Mo was almost one-third that of commercial pure $\mathrm{Ti}$ and $\mathrm{Ti6A14V}{ }^{9)}$ However, there are limited reports concerning metallic biomaterials with low

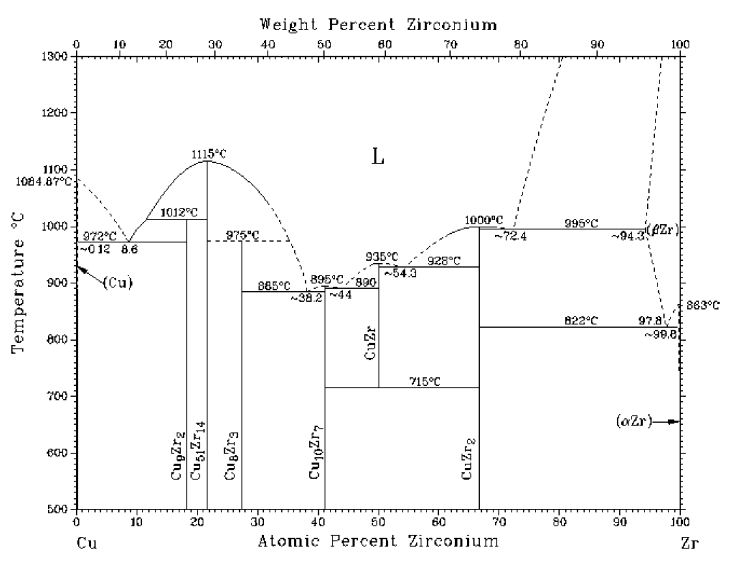

Fig. 1 Zr-Cu binary alloy phase diagram. ${ }^{10}$

magnetic susceptibility for dental applications. In this study, we investigate the magnetic susceptibility of $\mathrm{Zr}-\mathrm{Cu}$ binary alloys for their potential use as biomaterials with a nullifying magnetic property.

\section{Experimental Procedure}

The $\mathrm{Zr}-\mathrm{Cu}$ binary alloys were prepared using the arcmelting process with $\mathrm{Zr}$ (99.9 mass\%) strips and oxygen-free copper (99.99 mass\%). Figure 1 presents the $\mathrm{Cu}-\mathrm{Zr}$ binary alloy phase diagram. ${ }^{10)}$ Amorphous $\mathrm{Cu}-\mathrm{Zr}$ alloys have been reported within the composition range of 10 to $80 \mathrm{at} \% \mathrm{Zr}$ by several investigators. ${ }^{11)}$ Additionally, Zr-rich amorphous alloys have been known to exhibit superconductivity. Therefore, in this study, a series of alloys with nominal compositions of $\mathrm{Zr}-x \mathrm{Cu}(x=0,1,5,10,15$ in mass $\%)$ were prepared to avoid superconductive amorphous alloys. Alloy ingots with a mass of approximately $60 \mathrm{~g}$ were prepared using arc-melting under an argon atmosphere in a watercooled copper hearth. Each ingot was remelted and flipped 7 times to ensure compositional homogeneity.

The microstructures of the alloy ingots were examined using an optical microscope (OM, Zeiss: Axio Vert. A1) and an electron probe micro-alalyzer (EPMA, Shimadzu: 1600). 

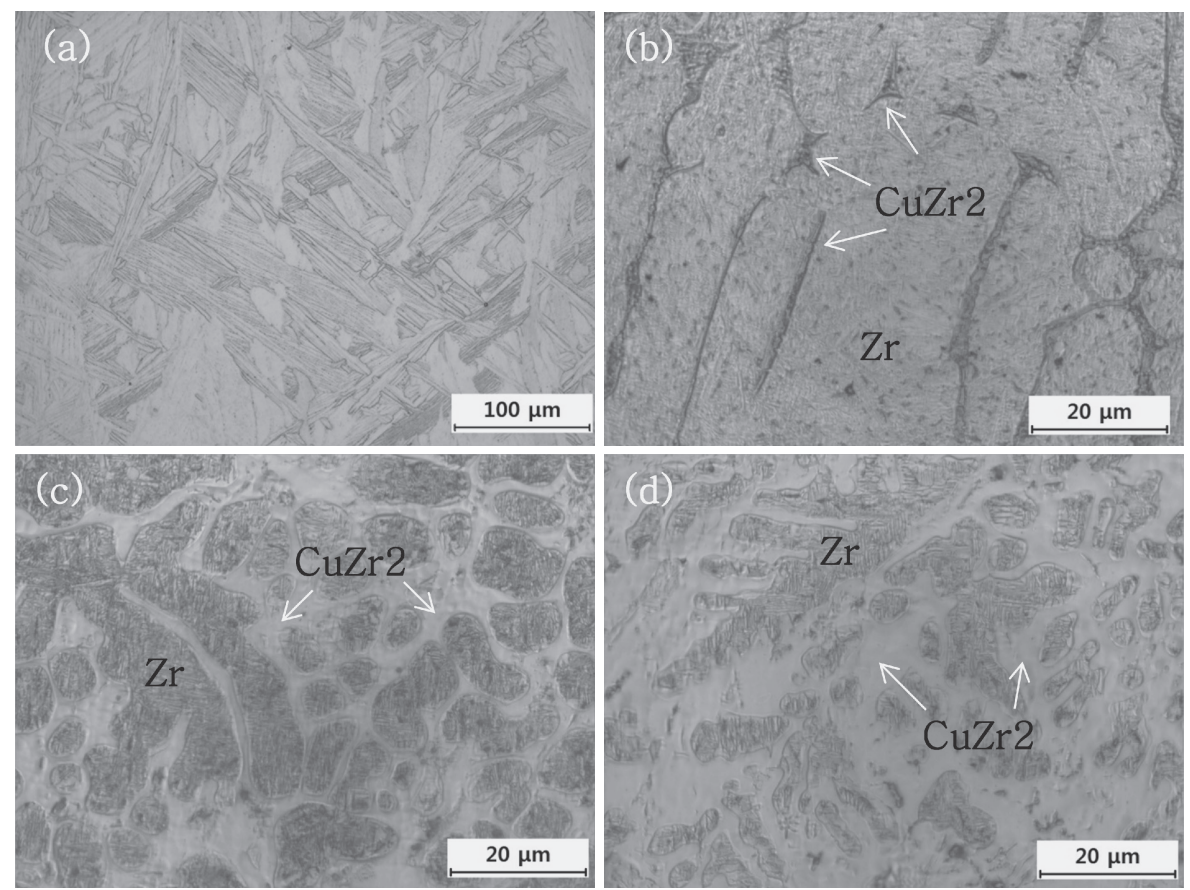

Fig. 2 Optical micrographs: (a) $\mathrm{Zr}$, (b) $\mathrm{Zr} 5 \% \mathrm{Cu}$, (c) $\mathrm{Zr} 10 \% \mathrm{Cu}$, and (d) $\mathrm{Zr} 15 \% \mathrm{Cu}$.

The specimens for microscopic analyses were cut from the ingots, mounted in epoxy resin using cold mounting, mechanically ground with emery paper (2400 grit) and then polished with alumina paste up to a $0.05 \mu \mathrm{m}$ colloidal suspension. The polished surfaces of the specimens were chemically etched in a solution consisting of $45 \mathrm{ml}$ of nitric acid and $10 \mathrm{ml}$ of hydrofluoric acid in distilled water for $7 \mathrm{~s}$. Crystallographic analysis of the test specimens was conducted using the X-ray diffraction technique to determine the phases in the alloy ingots. The diffraction patterns were obtained using a X-ray diffractometer (XRD, Rigaku: X'pert PRO MPD) with monochromatic $\mathrm{Cu}-K_{\alpha}$ radiation at $40 \mathrm{kV}$ and $30 \mathrm{~mA}$. The bulk density of the ingot samples was measured using an apparent density tester (Matsuhaku: $\mathrm{MH}-$ 124S) following ASTM C20-78 procedures.

Magnetic hysteresis curves were obtained from the alloy ingot sample using a vibrating sample magnetometer (VSM, Lake shore: 74046). The induced voltage, which is proportional to the magnetic moment of the sample, was obtained from the pickup coils attached to the electromagnet. By measuring in an external electromagnet field, it was possible to obtain the hysteresis curve and susceptibility of each ingot sample. The test specimens were machined with $7 \mathrm{~mm}$ long, $5 \mathrm{~mm}$ wide and $1 \mathrm{~mm}$ thick, and finally polished with the same process of microscopic analyses.

\section{Results and Discussion}

Figure 2 presents micrographs of the $\mathrm{Zr}-\mathrm{Cu}$ alloys. The $\mathrm{Zr}$ appears to have a single phase of $\alpha$-Zr with a basketweave and lamella microstructure, as shown in Fig. 2(a). With the addition of $\mathrm{Cu}$, the basketweave microstructure disappeared, and a two-phase microstructure was clearly observed. The dark gray phases (denoted to $\mathrm{CuZr}_{2}$ ) were surrounded by white phases (denoted to $\mathrm{Zr}$ ), and the white phase area grew

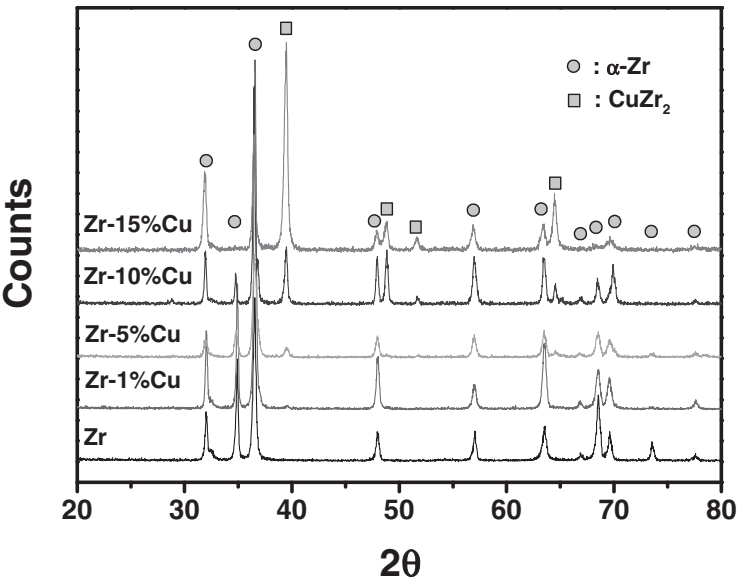

Fig. 3 X-ray diffraction profiles of as-cast $\mathrm{Zr}-\mathrm{Cu}$ alloys, which shows the dual phases.

with the addition of $\mathrm{Cu}$. The chemical composition of the $\mathrm{CuZr}_{2}$ phase was determined to be $66.1 \mathrm{Zr} 33.9 \mathrm{Cu}$ in $\mathrm{mol} \%$ by the wavelength dispersive spectroscopy analysis.

Figure 3 shows the XRD profiles of the as-cast $\mathrm{Zr}-\mathrm{Cu}$ alloys. The $\mathrm{Zr}$ without $\mathrm{Cu}$ addition only has peaks originating from the $\alpha-\mathrm{Zr}$ phase. However, $\mathrm{CuZr}_{2}$ diffraction peaks were observed upon adding $\mathrm{Cu}$, and the intensity of the peaks increased as the amount of $\mathrm{Cu}$ increased. This intermetallic compound has a tetragonal, $\mathrm{MoSi}_{2}$-type structure. ${ }^{14)}$ The $\mathrm{CuZr}_{2}$ phase fraction was measured quantitatively using image analysis. As demonstrated in Fig. 2, the $\mathrm{CuZr}_{2}$ phase increases as a function of the $\mathrm{Cu}$ element addition up to $40 \%$ area fraction at 15 mass $\% \mathrm{Cu}$.

Figure 4 shows the magnetic susceptibility of the as-cast $\mathrm{Zr}-\mathrm{Cu}$ alloys for each $\mathrm{Cu}$ addition and those from several references previously reported for implant materials. ${ }^{12)}$ The zirconium in this study exhibits nearly the same level of 


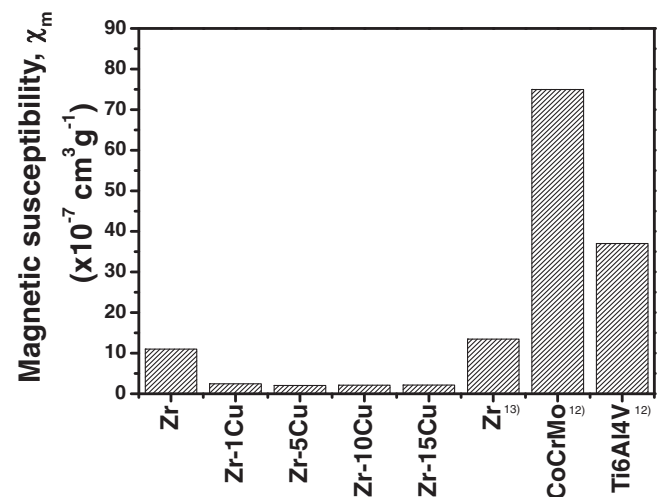

Fig. 4 Magnetic susceptibility of the as-cast $\mathrm{Zr}-\mathrm{Cu}$ alloys and other reference alloys.

magnetic susceptibility $\left(10^{-6}\right)$ as previously reported for pure Zr. ${ }^{13)}$ However, the magnetic susceptibility gradually decreased with only the addition of 1 mass $\% \mathrm{Cu}$ up to $77 \%$. Magnetic susceptibility of $\mathrm{Cu}$ is very small and the value is negative. ${ }^{14,15)}$ Therefore, the magnetic susceptibility of $\mathrm{Zr}-\mathrm{Cu}$ alloys may be suddenly decreased. With further increases in the $\mathrm{Cu}$ amount, the magnetic susceptibility decreased slightly. It may be the effect of $\mathrm{CuZr}_{2}$ phase that has superconductive property. ${ }^{16)}$ This result is significant and attractive for the application of these materials as biomaterials because this alloy permits the removal of artifacts caused by the magnetic properties of metallic biomaterials. All of the experimental alloys in this study exhibited extremely low magnetic susceptibility compared with that of previously reported materials, as shown in Fig. 4.

Both diamagnetic and paramagnetic materials are considered to be nonmagnetic because they exhibit magnetization only when in the presence of an external magnetic field. The alloying element $\mathrm{Cu}$ is a typical diamagnetic material, which exhibits an extremely weak form of magnetism that is nonpermanent and persists only while in an applied external field. The magnitude of the induced magnetic moment is extremely small and in a direction opposite to that of the applied field. In contrast, $\mathrm{Zr}$ is a typical paramagnetic material, and the orientation of its atomic magnetic moments is random in the absence of an external field. The magnitude of the induced magnetic moment is also relatively small.

The magnetic characteristic of human tissue is on the boundary between diamagnetic and paramagnetic materials. The magnetic susceptibility of human tissue is approximately $-9.05 \mathrm{ppm}^{17)}$ However, the most commercialized metallic alloying elements, such as $\mathrm{Zr}, \mathrm{Mo}, \mathrm{Ti}, \mathrm{Cr}$, and $\mathrm{Nb}$, are typical paramagnetic materials, and their magnetic susceptibilities are at an approximate level of $10^{-4}$ these alloying elements exhibit a low level of susceptibility compared with general metallic biomaterials, there is a large discrepancy between these alloying metals and human tissues. $\mathrm{Cu}$ is a typical diamagnetic material with extremely low magnetic suscepti- bility of approximately $-9.63 \mathrm{ppm}$, which is nearly the same level of susceptibility as human tissue. Thus, we designed and fabricated this $\mathrm{Zr}-\mathrm{Cu}$ binary alloy that consisted of diamagnetic and paramagnetic materials, which resulted in an extremely low magnetic susceptibility.

\section{Conclusions}

To investigate the magnetic susceptibility of $\mathrm{Zr}-\mathrm{Cu}$ binary alloys for their potential use as biomaterials with extremely low magnetic susceptibilities, test alloys were designed and fabricated. The following conclusions were drawn:

(1) The magnetic susceptibility of $\mathrm{Zr}-\mathrm{Cu}$ binary alloys is low and approximately one order less than that of pure $\mathrm{Zr}$ and other commercialized biomaterials.

(2) This binary alloy has two dominant phases, $\alpha$-Zr and a $\mathrm{CuZr}_{2}$ intermetallic phase. The fraction of intermetallic phases increased with the addition of $\mathrm{Cu}$ and exhibits a tetragonal structure.

\section{Acknowledgments}

This work was supported by the National Research Foundation of Korea (NRF) with a grant funded by the Korean government MSIP (No. 2008-0062283).

\section{REFERENCES}

1) M. A. Gepreel and M. Niinomi: J. Mech. Behav. Bio. Mater. 20 (2013) $407-415$.

2) K. Miura, N. Yamada, S. Hanada, T. K. Jung and E. Itoi: Acta Biomater. 7 (2011) 2320-2326.

3) Y. L. Zhou, M. Niinomi and T. Akahori: Mater. Sci. Eng. A 371 (2004) 283-290.

4) F. Shafiei, E. Honda, H. Takahashi and T. Sasaki: J. Dent. Res. 82 (2003) 602-606.

5) H. Hubálková, P. La Serna, I. Linetskiy and T. Dostálová: Int. Dent. J. 56 (2006) 135-141.

6) H. Imai, Y. Tanaka, N. Nomura, Y. Tsutsumi, H. Doi, Z. Kanno, K. Ohno, T. Ono and T. Hanawa: Acta Biomater. 9 (2013) 8433-8439.

7) Y. Gao, K. Muramatsu, A. Kushibe, K. Yamazaki, A. Chiba and T. Yamomoto: IEEE Trans. Magn. 45 (2009) 4837-4840.

8) R. Kondo, N. Nomura, Suyalatu, Y. Tsutsumi, H. Doi and T. Hanawa: Acta Biomater. 7 (2011) 4278-4284.

9) Suyalatu, N. Nomura, K. Oya, Y. Tanaka, R. Kondo, H. Doi, Y. Tsutsumi and T. Hanawa: Acta Biomater. 6 (2010) 1033-1038.

10) K. Okamoto: Desk Handbook: Phase Diagrams for Binary Alloys, 2nd ed., (ASM Int., 2010) p. 315.

11) T. R. Chen and P. Y. Lee: J. Marine Sci. Tech. 1 (1993) 59-64.

12) N. Nomura, Y. Tanaka, Suyalatu, R. Kondo, H. Doi, Y. Tsutsumi and T. Hanawa: Mater. Trans. 50 (2009) 2466-2472.

13) D. R. Lide: Magnetic Susceptibility of the Elements and Inorganic Compounds, CRC HandBook of Chemistry and Physics, 84th ed., (CRC Press, 2003-2004) Sec. 4-141.

14) R. Bowers: Phys. Rev. 102 (1956) 1486-1488.

15) E. H. Williams: Phys. Rev. 38 (1931) 828-831.

16) D. Okai, G. Motoyama, H. Kimura and A. Inoue: Phys. Proc. 27 (2012) $56-59$.

17) J. F. Schenck: Med. Phys. 23 (1996) 815-850. 